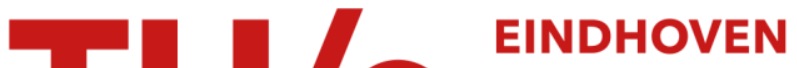 UNIVERSITY OF TECHNOLOGY
}

\section{Birefringence evaluation of multimode multilayer AIGaAs/AIAs waveguides}

\section{Citation for published version (APA):}

Leo, G., Secondini, M., Morabito, M., Rossi, de, A., Assanto, G., Fiore, A., Berger, V., Calligaro, M., \& Nagle, J. (2001). Birefringence evaluation of multimode multilayer AIGaAs/AlAs waveguides. Applied Physics Letters, 78(11), 1472-1474. https://doi.org/10.1063/1.1355005

DOI:

10.1063/1.1355005

Document status and date:

Published: 01/01/2001

\section{Document Version:}

Publisher's PDF, also known as Version of Record (includes final page, issue and volume numbers)

\section{Please check the document version of this publication:}

- A submitted manuscript is the version of the article upon submission and before peer-review. There can be important differences between the submitted version and the official published version of record. People interested in the research are advised to contact the author for the final version of the publication, or visit the $\mathrm{DOI}$ to the publisher's website.

- The final author version and the galley proof are versions of the publication after peer review.

- The final published version features the final layout of the paper including the volume, issue and page numbers.

Link to publication

\section{General rights}

Copyright and moral rights for the publications made accessible in the public portal are retained by the authors and/or other copyright owners and it is a condition of accessing publications that users recognise and abide by the legal requirements associated with these rights.

- Users may download and print one copy of any publication from the public portal for the purpose of private study or research.

- You may not further distribute the material or use it for any profit-making activity or commercial gain

- You may freely distribute the URL identifying the publication in the public portal.

If the publication is distributed under the terms of Article 25fa of the Dutch Copyright Act, indicated by the "Taverne" license above, please follow below link for the End User Agreement:

www.tue.nl/taverne

Take down policy

If you believe that this document breaches copyright please contact us at:

openaccess@tue.nl

providing details and we will investigate your claim. 


\title{
Birefringence evaluation of multimode multilayer AIGaAs/AIAs waveguides
}

\author{
G. Leo, M. Secondini, M. Morabito, A. De Rossi, ${ }^{\text {a) }}$ and G. Assanto ${ }^{\text {b) }}$ \\ Department of Electronic Engineering and National Institute for the Physics of Matter INFM-RM3, \\ Terza University of Rome, Via della Vasca Navale 84, 00146 Rome, Italy
}

A. Fiore, ${ }^{\text {c) }}$ V. Berger, M. Calligaro, and J. Nagle

Thomson-CSF, Laboratoire Central de Recherches, Domaine de Corbeville, 91400 Orsay, France

(Received 17 October 2000; accepted for publication 17 January 2001)

\begin{abstract}
We investigate surface-emitting second harmonic generation as a powerful technique for the evaluation of birefringence in optical waveguides supporting several modes. This one-shot diagnostic is demonstrated at $1319 \mathrm{~nm}$ in multilayer AlGaAs waveguides, before and after the lateral oxidation of AlAs layers. (C) 2001 American Institute of Physics.
\end{abstract}

[DOI: $10.1063 / 1.1355005$ ]

Nowadays material and device characterization for integrated optics has to face more and more stringent requirements, due to the tighter and tighter design compliances of state-of-the-art resonant/phase-matched devices. In spite of this, however, characterization tools are still essentially based on the measurement of waveguide effective indices and losses. ${ }^{1}$ Concerning waveguide design, significant efforts have been recently undertaken to tailor modal birefringence (MB) with two main goals: (i) MB minimization for fibercompatible, polarization-degenerate devices through geometrical compensation of material anisotropy; ${ }^{2}$ (ii) controlled MB through form birefringence, for phase matching in parametric wavelength generators. ${ }^{3}$

In this letter we describe a one-shot technique which allows the simultaneous measurement of the TE/TM birefringence of all the eigenmodes supported by a multimode optical waveguide in a quadratically nonlinear composite semiconductor. Our approach exploits surface emitting second harmonic generation (SESHG), first demonstrated in 1981 using Ti:LiNbO ${ }_{3}$ waveguides. ${ }^{4}$ SESHG has been later employed in GaAs/AlGaAs, ${ }^{5}$ and more recently in selectively oxidized GaAs/AlAs multilayers. ${ }^{6}$ The main concept underlying SESHG is sketched in Fig. 1 for a slab waveguide: the wave vector mismatch $\Delta \beta=\beta^{+}-\beta^{-}$between two nonlinearly interacting, counter-propagating eigenmodes at the fundamental frequency $\omega$ sets the out-of-plane emission angle $\theta$ for the radiated second harmonic $2 \omega$. This angle relates to the sought information on $\mathrm{MB}$, i.e., the difference $\Delta N$ $=2 \sin \theta$ between the effective indices of the counterpropagating fields at $\omega$. The relation between these fields and the nonlinear polarization $\mathbf{P}^{(2 \omega)}$ can be conveniently cast in the scalar form $P^{(2 \omega)}=2 \varepsilon_{0} d_{\mathrm{eff}} E^{+} E^{-}$, where $\varepsilon_{0}$ is the dielectric permittivity of vacuum and the effective coefficient $d_{\text {eff }}$ depends on both the tensor structure and the polarizations of the coupled fields at $\omega, \mathbf{E}^{+}$and $\mathbf{E}^{-}$, respectively. Hereby, we refer to a GaAs-based guiding structure on (100) substrates, with $d_{\mathrm{eff}}=d_{123}$, where SESHG is driven by the nonlinear

\footnotetext{
${ }^{a}$ Present address: Thomson-CSF, Laboratoire Central de Recherches, Domaine de Corbeville, 91400 Orsay, France.

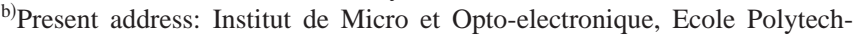
nique Federale de Lausanne, CH-1015 Lausanne, Switzerland.

${ }^{c)}$ Electronic mail: assanto@ele.uniroma3.it
}

interaction of a TE with a TM mode oppositely propagating along the waveguide, with $\Delta \beta=\beta_{\mathrm{TE}}-\beta_{\mathrm{TM}}$. The simplest approach to excite SESHG consists in launching both TE and TM eigenfields at one input facet of the sample, exploiting the $\sim 30 \%$ Fresnel reflection at the opposite semiconductor/ air interface in order to generate the required counterpropagating cross-polarized modal components at $\omega$. In this case, pictured in Fig. 2, two distinct out-of-plane emissions take place due to the interactions $E_{\mathrm{TE}}^{+}-E_{\mathrm{TM}}^{-}$and $E_{\mathrm{TM}}^{+}-E_{\mathrm{TE}}^{-}$, respectively. These are associated with a stationary nonlinear polarization wave

$$
\begin{aligned}
P^{(2 \omega)} \propto & E_{\mathrm{TE}} E_{\mathrm{TM}} \\
= & \left(A_{\mathrm{TE}}^{+} e^{-i \beta_{\mathrm{TE}}}+A_{\mathrm{TE}}^{-} e^{i \beta_{\mathrm{TE}}}\right)\left(A_{\mathrm{TM}}^{+} e^{-i \beta_{\mathrm{TM}^{z}}}+A_{\mathrm{TM}}^{-} e^{i \beta_{\mathrm{TM}^{z}}}\right) \\
= & A_{\mathrm{TE}}^{-} A_{\mathrm{TM}}^{+} e^{i \Delta \beta z}+A_{\mathrm{TE}}^{+} A_{\mathrm{TM}}^{-} e^{-i \Delta \beta z} \\
& +A_{\mathrm{TE}}^{+} A_{\mathrm{TM}}^{+} e^{-i\left(\beta_{\mathrm{TE}}+\beta_{\mathrm{TM}}\right) z}+A_{\mathrm{TE}}^{-} A_{\mathrm{TM}}^{-} e^{i\left(\beta_{\mathrm{TE}}+\beta_{\mathrm{TM}}\right) z} \\
\approx & 2 r A_{\mathrm{TE}}^{+} A_{\mathrm{TM}}^{+} \cos (\Delta \beta z)
\end{aligned}
$$

with $r=A_{\mathrm{TE}}^{-} / A_{\mathrm{TE}}^{+} \approx A_{\mathrm{TM}}^{-} / A_{\mathrm{TM}}^{+}$. The relevant term of $P^{(2 \omega)}$ is the source of a surface-emitted field at $2 \omega$, with $P^{(2 \omega)}$ $\propto \cos (\omega \Delta N z / c)$. It is therefore possible to evaluate the birefringence $\Delta N$ at $\omega$ by fringe counting in the near-field distribution of the harmonic $I^{(2 \omega)}(z) \propto\left|P^{(2 \omega)}\right|^{2}$, varying sinusoidally with period $\lambda / 2 \Delta N .{ }^{5,6}$ In a multimode waveguide, however, several TE-TM interactions can give rise to SESHG. While each (sign-reversed) pair produces a distinct (near-field) sinusoidal fringe pattern at $2 \omega$, the visibility of

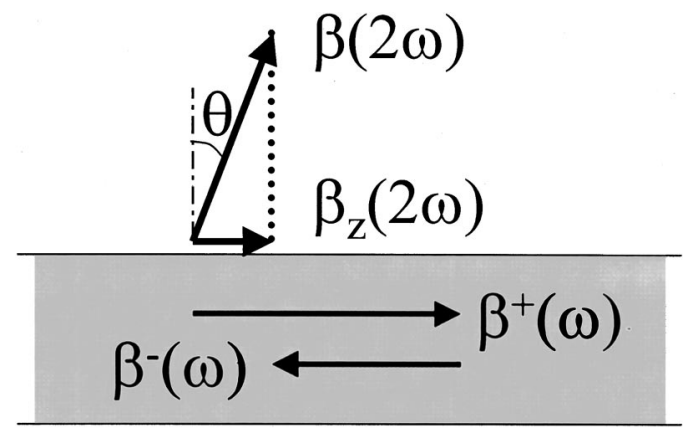

FIG. 1. Phase-matching scheme of SESHG at frequency $2 \omega$ from two nonlinearly interacting guided-wave fields at $\omega$. 


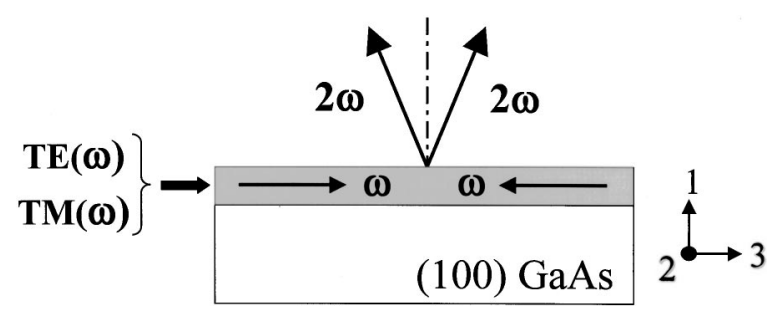

FIG. 2. Sketch of SESHG with two out-of-plane emissions at opposite angles.

each depends strongly on: end-fire mode excitations, overlap integral between the counter-propagating fields associated with each SESHG process, coherence length and Maker-like interference in the second harmonic field at each depth within the thickness of the nonlinear film. ${ }^{7}$ For different launch conditions at $\omega$, therefore, the near field at $2 \omega$ appears as either a single fringe system (fundamental mode coupling, $\mathrm{TE}_{00}-\mathrm{TM}_{00}$ interactions), or a superposition of sinusoidal patterns (several mode couplings). In the latter case, the Fourier-transformed intensity distribution $I^{(2 \omega)}$ in the far field can spatially resolve the phase-matched components originated by the corresponding SESHG processes, such that one observation can provide complete information on both birefringence and modal content of multimode waveguides.

To ascertain the applicability of the above approach, we performed experiments on AlGaAs waveguides. Samples were realized by molecular beam epitaxy according to the following structure: $\mathrm{Al}_{0.7} \mathrm{Ga}_{0.3}$ As (substrate)/AlAs $(200 \mathrm{~nm}$ )/ $2 \times\left[\mathrm{Al}_{0.1} \mathrm{Ga}_{0.9} \mathrm{As}(270 \mathrm{~nm}) / \mathrm{AlAs}(25 \mathrm{~nm})\right] / \mathrm{Al}_{0.1} \mathrm{Ga}_{0.9} \mathrm{As} \quad(270$ $\mathrm{nm}) / \operatorname{AlAs}(62 \mathrm{~nm}) / \mathrm{Al}_{0.7} \mathrm{Ga}_{0.3} \mathrm{As}(300 \mathrm{~nm}) / \mathrm{GaAs}(20 \mathrm{~nm})$. The planar structures were reactively ion etched to create 1- $\mu \mathrm{m}$-thick ridges with 3-9 $\mu \mathrm{m}$ widths and cleaved for endfire excitation. For the measurements, we launched $100 \mathrm{ps}$ pulses at $\lambda=1.32 \mu \mathrm{m}$ from a continuous wave (cw) modelocked Nd-yttrium-aluminum-garnet laser (repetition rate $82 \mathrm{MHz}$ ) into the waveguides, using linearly polarized light at $45^{\circ}$ relative to the substrate. With samples a few $\mathrm{mm}$ long, such pulse durations allow a quasi-cw interaction between the oppositely propagating waves. The ridges supported the four lowest-order quasi-TE and TM modes, and the light due to SESHG at $\lambda=0.66 \mu \mathrm{m}$ was collected by a charge coupled device (CCD) camera (a $4.8 \mathrm{~mm} \times 3.6 \mathrm{~mm} \mathrm{Si}$ array, with image resolution limited by a $320 \times 240$ pixel acquisition board).

The near-field measurement is illustrated in Fig. 3(a), where we also sketched the nonlinear polarization pattern. In the near field and for a sample length $L=3.23 \pm 0.02 \mathrm{~mm}$, counting $m=68.5 \pm 0.5$ fringes [see Fig. 4(a)], from $\Delta N$ $=m \lambda / 2 L$ we could obtain the birefringence between the two fundamental modes: $N\left(\mathrm{TE}_{00}\right)-N\left(\mathrm{TM}_{00}\right)=0.0140 \pm 0.0002$. For the relative uncertainty

$$
\left|\frac{d(\Delta N)}{\Delta N}\right|=\left|\frac{d m}{m}\right|+\left|\frac{d L}{L}\right|+\left|\frac{d \lambda}{\lambda}\right|,
$$

a typical value of $1.5 \%$ was achieved, the first term being the dominating one. In the conservative hypothesis that only an integer number of fringes could be counted in the image, any efforts to reduce the second term below $|\mathrm{dm} / \mathrm{m}|=0.5 / \mathrm{m}$ proved not worthwhile, whereas the third term is typically Downloaded 04 Mar 2008 to 131.155 .151 .52 . Redistribution subject

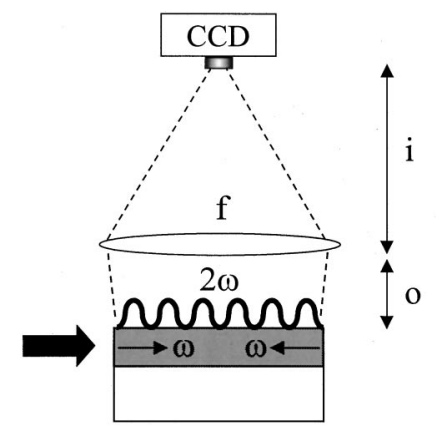

(a)

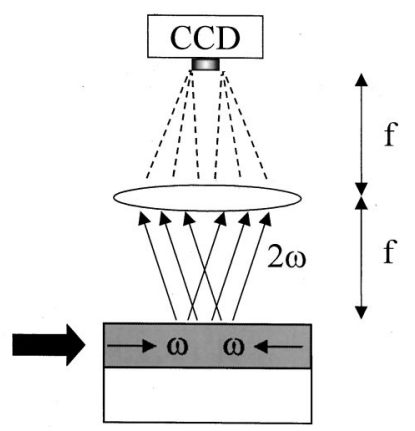

(b)
FIG. 3. MB evaluation through the detection of SESHG in: (a) near field, (b) far field.

much smaller than the first two. The overall figure [Eq. (2)] could be improved not only by increasing the pixel density, but also by using longer samples, provided that losses are negligible (as in our case, with typical values lower than 1 $\mathrm{dB} / \mathrm{cm})$.

In order to acquire the image of the far-field pattern, as sketched in Fig. 3(b), the SESHG was imaged onto the CCD with a lens of focal length $f=2.5 \mathrm{~cm} .{ }^{6}$ Because of the CCD finite aperture $w$, the choice of $f$ follows from the maximum amount of birefringence to be measured $\left(f \leqslant w / \Delta N_{\max }\right)$. A typical result is shown in Fig. 4(b), where each pair of $\delta$ functions (Fourier transform of a sinusoid) refers to the corresponding set of counter-propagating modes. While the vertical extent of the $\delta \mathrm{s}$ is due to diffraction from the finite width of the ridge, lateral confinement bears no discernible effects on the observed pattern with respect to the case of a planar waveguide. From Fig. 4(b) it is straighforward to infer the value of MB for each couple of eigenmodes, as the ratio of the distance $D_{i j}$ between the corresponding $\delta \mathrm{s}$ and the focal length, as presented in Table I. The case $N\left(\mathrm{TE}_{10}\right)$ $-N\left(\mathrm{TM}_{10}\right)$, although not visible in the photograph, was readily obtained by slightly changing the launch conditions,

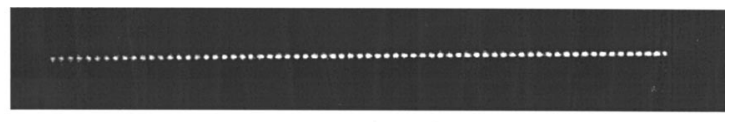

(b)
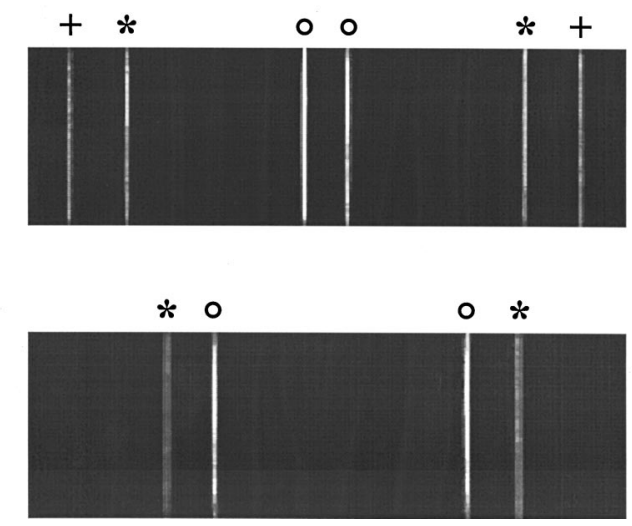

FIG. 4. (a) Typical near-field intensity distribution $I^{(2 \omega)}$. (b) Far-field picture of SESHG modes from an AlGaAs ridge $7 \mu \mathrm{m}$ wide, for $\mathrm{TE}_{00}-\mathrm{TM}_{00}$ $(\bigcirc), \mathrm{TE}_{10}-\mathrm{TM}_{00}(*), \mathrm{TE}_{00}-\mathrm{TM}_{10}(+)$. (c) Same as (b), after selective oxidation of AlAs layers.

to AIP license or copyright; see http://apl.aip.org/apl/copyright.jsp 
TABLE I. Measured and calculated TE-TM modal birefringences.

\begin{tabular}{ccc}
\hline \hline Interacting modes & Measured $\Delta N$ & Calculated $\Delta N$ \\
\hline $\mathrm{TE}_{00}-\mathrm{TM}_{00}$ & $0.0138 \pm 0.0008$ & $0.014 \pm 0.001$ \\
$\mathrm{TE}_{10}-\mathrm{TM}_{00}$ & $0.125 \pm 0.002$ & $0.122 \pm 0.002$ \\
$\mathrm{TE}_{00}-\mathrm{TM}_{10}$ & $0.160 \pm 0.002$ & $0.158 \pm 0.002$ \\
$\mathrm{TE}_{10}-\mathrm{TM}_{10}$ & $0.0220 \pm 0.0008$ & $0.022 \pm 0.001$ \\
\hline \hline
\end{tabular}

and is also listed in the table. The uncertainties here are associated with both $f$ and $D$

$$
\left|\frac{d\left(\Delta N_{i j}\right)}{\Delta N_{i j}}\right|=\left|\frac{d\left(D_{i j}\right)}{D_{i j}}\right|+\left|\frac{d f}{f}\right| .
$$

While $|d f / f|=1 \%$ after the manufacturer's specifications, the first term on the right-hand side of Eq. (3) depends on pixel discretization, i.e., on the resolution of both CCD and acquisition board. In fact, distances are measured in pixels (in our case the pixel size was $d_{p}=15 \mu \mathrm{m}$ ), and the relative uncertainty $|d D / D| \approx d_{p} / D$, which is lower for wider separated $\delta^{\prime} \mathrm{s}$. The overall error ranges from $1.5 \%$ to $3 \%$, with a smaller contribution given by the finite linewidths in the far field ( $\sim 5 \mu \mathrm{m}$ due to the finite waveguide length), and a negligible one by absorption.

In Table I the calculated $\Delta N^{\prime}$ s and related uncertainties are also listed, as derived from Afromowitz's dispersion model $^{8}$ (due to the ridge aspect ratio, a slab-waveguide mode solver was more than adequate). As apparent from Table I, this simple single-shot technique allows the accurate estimate of birefringence between all the existing modes at $\omega$, in excellent agreement with model predictions.

Finally, we employed SESHG to investigate waveguides with a higher birefringence, i.e., AlGaAs/AlAs samples (as described above) after lateral oxidation of the AlAs layers. ${ }^{9}$ In general, due to form birefringence, the field in low-index layers is higher for TM than for TE polarization. ${ }^{3,6,10}$ It is therefore expected that by selectively lowering the refractive indices of thin AlAs layers, the effective indices of TM modes decrease more than TE. This is experimentally verified and visible in Fig. 4(c), where two features are noticeable: on the one hand the $\mathrm{MB}$ between $\mathrm{TE}_{00}$ and $\mathrm{TM}_{00}$ is greatly enhanced by oxidation, from 0.0138 to $0.08 .{ }^{3}$ On the other hand, while $N\left(\mathrm{TE}_{10}\right) \ll N\left(\mathrm{TM}_{00}\right)$ in the as-grown samples, oxidation lowers $N\left(\mathrm{TM}_{00}\right)$ far more than $N\left(\mathrm{TE}_{10}\right)$, thus reducing the corresponding $\mathrm{MB}$ from 0.125 to 0.11 . Line pairs associated with larger $\Delta N^{\prime}$ s fell outside the CCD field of view. Due to incomplete oxidation of AlAs layers through our process, such $\mathrm{MB}$ values were inferred from the experiment by assuming $n\left(\mathrm{AlO}_{x}\right)=1.61,{ }^{11}$ and using the oxide penetration distance as a fitting parameter.

In conclusion, we have demonstrated that SESHG can be effective in characterizing modal birefringence of nonlinear waveguides with high accuracy. This technique is a valuable complement to standard $m$-line evaluation, ${ }^{10}$ and allows a precise spectral determination of phase mismatch in structures for parametric generation.

This research was funded by the European Union (ESPRIT Project OFCORSE II).

${ }^{1}$ See, for example, P. Martin, E. M. Skouri, L. Chusseau, C. Alibert, and H. Bissessur, Appl. Phys. Lett. 67, 881 (1995).

${ }^{2}$ W. P. Wong and K. S. Chiang, J. Lightwave Technol. 16, 1240 (1998).

${ }^{3}$ A. Fiore, V. Berger, E. Rosencher, P. Bravetti, and J. Nagle, Nature (London) 391, 463 (1998)

${ }^{4}$ P. J. Vella, R. Normandin, and G. I. Stegeman, Appl. Phys. Lett. 38, 759 (1981).

${ }^{5}$ D. Vakhshoori, M. C. Wu, and S. Wang, Appl. Phys. Lett. 52, 422 (1988).

${ }^{6}$ A. Fiore, V. Berger, E. Rosencher, S. Crouzy, N. Laurent, and J. Nagle, Appl. Phys. Lett. 71, 2587 (1997).

${ }^{7}$ N. D. Whitbread and P. N. Robson, IEEE J. Quantum Electron. 30, 139 (1994).

${ }^{8}$ M. A. Afromowitz, Solid State Commun. 15, 39 (1974).

${ }^{9}$ J. M. Dallesasse, J. N. Holonyak, A. R. Sugg, T. A. Richard, and N. El-Zein, Appl. Phys. Lett. 57, 2844 (1990).

${ }^{10}$ G. Leo, C. Caldarella, G. Masini, A. De Rossi, G. Assanto, O. Durand, M. Calligaro, X. Marcadet, and V. Berger, Appl. Phys. Lett. 77, 3884 (2000).

${ }^{11}$ F. Sfigakis, P. Paddon, V. Pacradouni, M. Adamcyk, C. Nicoll, A. R. Cowan, T. Tiedje, and J. F. Young, J. Lightwave Technol. 18, 199 (2000). 